\title{
LA HISTORIA, LA CIENCIA Y EL METODO (Notas sobre Max Weber)
}

\author{
Juan Rico Giménez \\ Universidad de Alicante
}

La lectura del libro de Anthony Giddens, El capitalismo y la moderna teoria social (1), produjo en mí la demostración de lo que el propio Giddens y muchos estudiosos actuales afirman, a saber, el interés que aún hoy suscitan el pensamiento y la obra weberianas. Así, en efecto, las presentes notas no tienen otro valor ni interés que testimoniar, de una manera sucinta y sin excesivas pretensiones cientificas, el eventual «encantamiento» que sufrió mi espíritu en torno a algunos temas cuyo planteamiento, en justicia, hay que atribuir a uno de los más reconocidos "padres» de la teoría social moderna. Pero todo testimonio, si además es público, encierra una segunda intención, que, por supuesto, éste no pretende soslayar: la de explicar, es decir, complicar a otras opiniones en los planteamientos propios, dentro de lo que Foucault llama el "espacio limitado de comunicación» (2). Terminaré esta parca introducción añadiendo que, al nivel de la bibligrafía, me he basado fundamentalmente en los análiss de Giddens y en poco más, como se verá. Del propio Max Weber he tenido en cuenta tres de sus más famosas obras: La ética protestante y el espíritu del capitalismo (3); Economía y Sociedad (4), y El político y el científico (5).

\footnotetext{
(1) Barcelona, Labor, 1977.

(2) La arqueología del saber, Mexico, Siglo XXI, 1978, p. 214.

(3) Barcelona, Península, 1979.

(4) Mexico, Fondo de Cultura Económica, 1977, E vols.

(5) Madrid, Alianza, 1975.
} 
De acuerdo con Raymond Aron (6), "Los quince últimos años del s. $X I X$, que son para Max Weber la época de formación entre los veinte $y$ los treinta y cinco, están marcados por el desarrollo de la legislación social....".

Tal aflrmación, además de cierta, es lógica si tenemos en cuenta que aquellos fueron los años de consolidación de la unidad nacional alemana, y que no hay proceso de consolidación de un Estado sin que el aparato legal-normativo sea uno de sus más importantes elementos constitutivos.

«El desarroillo de la. legislación social»... He aquí una de las piedras de toque en la formación intelectual y metodológica de Weber. Al parecer, intuyó muy pronto que para comprobar la primordial importancia que el derecho ejercia y había ejercido en la transformación económica, social y política de un grupo humano, lo mejor era hacer la sociología de aquel, en el sentido de establecer las relaciones, más que causales, dialécticas, entre determinadas formas de acción colectiva o individual y la legislación vigente. La relación causal, así, no era determinista ni unilineal en el sentido del mecanicismo y el marxismo burdos, sino coyuntural y ambivalente, de acuerdo con las circunstancias. De manera que, en el fondo, siempre estaba la historia o, mejor dicho, la imaginación cientifica de la historia; ¿por qué determinada ley o cuerpo legal influyó en la transformación de ciertos actos individuales y colectivos y por qué en ese sentido y en ese momento?; ¿०, por qué determinadas actitudes, opiniones, etc., "nuevas» acaban provocando una transformación legal en un espacio y un tiempo dados y no en otros? Aventurándonos, quizá, en nuestro análisis, todo da la impresión, leyendo a Max Weber, de que con tanta fuerza como intentó combatir y aclarar científicamente cualquier determinismo, con más ahínco quiso desterrar de la epistemología científica el concepto de azar, de imponderable. El científico social, (recomendaría Weber), quizá más que ningún otro, precisamente por la verstilidad de su objeto, debe basar su metodología en el cálculo (retrospectivo, cuando se indaga el pasado), de todas aquellas posibilidades que permitan reconstruir lógicamente ( = racionalmente) la realidad. Lo que no presupone en Weber la ingenuidad de inferir que la verdadera forma de conocimiento sea la deductiva:

"La metodología weberiana del tipo ideal no propone, como se supo-

(6) Prólogo a El político y el científico, cit., p. 9. 
ne gratuitamente cuando se le reprocha su constructivismo, un instrumento de prueba que debería sustituir a la investigación de las regularidades empíricas o el trabajo histórico de la búsqueda de causas. Cuando se trata de explicar constelacione históricas singulares (formaciones sociales, configuraciones culturales o acontecimientos), las construcciones típico-ideales del sociólogo pueden prestar ayuda para llegar a la formulación de hipótesis y sugerir las preguntas que se plantearán a la realidad; no podrían, en cambio, proveer por sí mismas ningún conocimiento de la realidad» (7).

$\mathrm{Ni}$ tampoco se infiere que deba restringirse el campo de investigación a los fenómenos estrictamente «racionales». De otra manera, si el científico quiere "totalizar» la realidad fenomenológica, analizándola empíricamente con la ayuda metodológica de los «tipos ideales» (y/o de los «tipos promedio» o "estadísticos»), debe considerar con la misma pertinencia tanto los elementos "racionales" de esa realidad como los «irracionales», siempre que puedan ser sometidos a un proceso científico de contrastación. Precísamente la simultaneidad de la metodología weberiana para tratar "relaciones inteligibles» diversas, es uno de los puntos que Aron (8) subestima en Weber, pensando aquel, tal vez con razón, y habida cuenta del proceso de complejización y especialización de las llamadas ciencias sociales, que tales «relaciones inteligibles» diversas requieren también diversos aparatos metodológicos. No vamos nosotros a quitar mérito a Aron para depositarlo en Weber, ni al revés. Ambos se mueven en épocas en extremo diferentes, y la que tocó al alemán se desplegó de tal forma que, si consideramos adecuadamente tal despliegue, probablemente comprenderemos mejor la figura y las contradicciones de ese pensador que, de no haber sido original y profundo, ahora estaría archivado en las arcas del olvido en lugar de seguir siendo materia polémica en los escritos de teoría sociológica o justificar cursos universitarios.

En efecto, Max Weber llegó a la madurez intelectual en el decenio inmediatamente posterior a la muerte de Marx, cuando las teorizaciones de los marxistas estaban adoptando posiciones doctrinales (gracias fundamentalmente a Engels, Kautsky y otros), diferentes de las que el propio Marx sostuvo, y ellod ebido, probablemente (situación que, a su vez, condicionó tales posiciones y las proyecciones de estas, los partidos), a transformaciones, tanto en la esfera política (ascenso del nacionalismo como ideología), como en la economía (imperialismo, cam262.

(7) BORDIEU, CHAMBOREDON, PASSERON, El oficio de sociólogo, Madrid, 1976, p.

(8) op. cit, p. 16. 
bio en la actitud empresarial respecto a las condiciones del obrero, capitalismo financiero nuevo, influjo de experiencias sindicales de nuevo cuño, etc.). Para Weber, el fenómeno "capitalismo" seguía siendo, como lo fue para Marx, el más importante de la historia occidental. En ese sentido, y dado que Weber, por su ventaja generacional, podia observar el incumplimiento de algunas de las profecías de Marx, justificó la necesidad de replantear de nuevo la reflexión política, tarea a la que, al parecer, dedicó la mayor parte de sus energías. En tal contexto comparativo, para nosotros-una vieja cuestión sigue vigente; ¿quién de los dos abarcó más campo de la realidad, Weber o Marx, lo que vale a decir, cuál de los dos manejó un instrumental más científico? En la medida en que las dos grandes (y viejas) ideologias, la burguesa y la marxista, siguen atrincherándose tras las explicaciones científicas, las respuestas continúan siendo multívocas y dudosas. Si, en cambio, pretendemos superar las limitaciones «opticas» de tales atrincheramientos, creemos poder afirmar que ambas interpretaciones, la de Marx como la de Weber, representan, salvo excepciones (casi siempre detectables en el nivel de lo profético y valorativo), auténticos hitos en la producción intelectual de Occidente. En todo caso, y respecto a Weber, cabe preguntarse: su instrumental metodológico, adoptado como alternativa cientifica al marxismo, ¿tenía supuestos únicamente científicos o intervenían también factores políticos e ideológicos? No hay duda de que Weber intenta insistentemente aclarar la cuestión delimitando el papel del político y el del científico y justificando tal delimitación en virtud precísamente de un mejor servicio a la verdad y la justicia. Lo que no ha impedido a las corrientes críticas e historiográficas posteriores adscribirle a la teoría burguesa, del mismo modo que al parcialmente frustrado profeta Marx se le instala automáticamente en las primeras filas del pensamiento revolucionario. Ello hasta hace poco por lo menos, ya que, en las últimas décadas, ambos pensadores están siendo releídos un poco más irrespetuosamente, desde fuera de las filas de sus incondicionales, con el consiguiente ensanchamiento del campo de la crítica y el saber. Como el propio Weber proponía, siempre es buena la tarea de desmitificar y desencantar de vez en cuando.

La metodología que un escritor va perfilando poco a poco está en función directa, tanto de sus influencias biográfico-pedagógicas, como de los temas de estudio a los que dedica las primeras y sostenidas atenciones. En el caso de Weber ello es claro:

"Los primeros escritos académicos de Weber versan sobre la historia 
legal y económica. No obstante, trabajos que parecen ser puramente académicos (como la disertación sobre la tenencia de tierras en la antigua Roma, escrita en 1891), contenían de hecho implicaciones sociales y políticas más amplias de su pensamiento. En sus tesis, Weber rechazaba el punto de vista adoptado por algunos estudiosos de la época, según el cual la historia económica de Roma constituia un conjunto único de acontecimientos absolutamente imposible de analizar a partir de los conceptos extraídos de otras situaciones; y descubrió en la estructura social y económica de Roma alguna de las características que se manifestarían posteriormente en la formación del capitalismo en la Europa de comienzos de la Edad Moderna (9)».

Vemos, pues, que de la historia, la jurisprudencia y la economía, como temas básicos de estudio, saca principalmente Weber su material metodológico. Sin olvidar de situar tales intentos dentro de «la controversia entonces en boga sobre la relación entre las ciencias naturales y las ciencias sociales y humanas» (10), a lo que hay que añadir el rechazo weberiano de la ortodoxia positivista comtiana.

A partir de esos primeros estudios se comprueba en Weber una preocupación permanente sobre la «complicada naturaleza de las relaciones entre la estructura económica y los demás aspectos de la organización social» (11), reorientando su atención hacia la problemática propia de la Europa capitalista, de la que Alemania constituía ya un prototipo. De ello dan medida sus estudios en profundidad sobre el mundo comercial y el de las finanzas y la bolsa (considerando la función económica mediadora de ésta, importantísima para la dinamización capitalista).

Sin embargo, tales planteamientos metodológicos difieren de los de Marx en un matiz: en el rechazo, por parte de Weber, de todo determinismo económico simplista. El asunto está en saber, una vez más, qué fenómeno actúa como dinamizador y con qué intensidad, si uno situado en la estructura económica, u otro desde la superestructura ideológica. Una aclaración la da el estudio weberiano de la transformación socioprofesional del antiguo aparcero en moderno jornalero: el deseo de cambio de aquel para convertirse en éste no tiene una motivación económica predominante, puesto que de ser poseedor (aunque parcialmente, y no propietario), a ser asalariado, la rentabilidad económica es negativa o, al menos, incierta a largo plazo (entre otras cosas, debido a la mayor inestabilidad en el empleo). La causa para el cambio, pues, es

(9) A. GIDDENS, Política y Sociología en Max Weber. Madrid, 1976, p. 14.

(10) A. GIDDENS, El capitalismo y... cit., p. 225.

(11) ibid., p. 208. 
primordialmente ideológica, al menos en un primer momento: el deseo de conseguir la «libertad».

Max Weber ve, no obstante, que ello no quiere decir que tales deseos e ideas no tengan nada que ver con los cambios económicos. Antes bien, «el nexo de las relaciones entre las ideas y los intereses materiales rara vez se puede especificar en términos de una procederílá causal de un nivel a otro en un solo sentido» (12).

La cónclusión de Weber, como la de Marx, sería la de la existencia de una estructura dialéctica entre relaciones económicas y formas de pensamiento, incidiendo en grados diversos unas sobre otras, según las circunstancias. Así, volviendo al anterior ejemplo de los aparceros y los jornaleros, una metodología adecuada ha de tener en cuenta, para cada momento y cada grupo, tanto las condiciones materiales de vida como las aspiraciones. De este modo puede proponerse una tipologia, en opinión de Weber, bastante correcta, aunque revisable siempre:

APARCERO - aceptación de los modelos tradicionales de respeto y protección.

JORNALERO - rechazo de tales modelos y actitud nueva de individualismo económico y liberación.

Por otra parte, en sus estudios de sociología de la religión, tiene Weber ocasión, una vez más, de corroborar el relativismo dialéctico-causal a que venimos refiriéndonos. En ese sentido, la ideología de una parte del primer protestantismo, el llamado "ascético» (calvinistas, pietistas, metodistas, baptistas...), como moral trascendente desencantada y negativa, hasta el punto de situar la única forma de salvación en una férrea. disciplina de trabajo, ahorro y frugalidad, habría de tener, aplicada a la producción, profundas consecuencias en el modo de producción capitalista, las más importantes de las cuales serían la acumulación de capital y el crecimiento económico constante: "La acumulación de riqueza se condena moralmente solo en la medida en que constituye una incitación al lujo y a la pereza; cuando las ganancias materiales se adquieren por medio del cumplimiento ascético del deber profesional, no solamente son toleradas, sino recomendadas de hecho moralmente» (13).

Pero Weber no se queda ahí y añade, en su obsesión por huir de conclusiones deterministas, que tales hechos no son consecuencias lógicas, sino psicológicas de la ideología protestante-ascética (pone el ejemplo de que la misma doctrina de la predestinación en el Islam no lleva al capitalismo, sino al desinterés por éste a favor de la guerra santa).

(12) ibid., p. 211.

(13) ibid., p. 220. 
Asi, Weber, cuando ve que el poderoso instrumento de la lógica flaquea, hecha mano de la psicología, por lo visto la única capaz (sin abandonar la lógica, ya que de lo contrario se entraría en el terreno de la intuición, que combatió siempre), de explicar ese misterioso sedimento de la conciencia que, a veces, tanta influencia tiene en el comportamiento y la mentalidad de los hombres.

Parecería que Weber llega inevitablemente a un callejón sin salida en sus intentos metodológicos. Pero no es así, y nosotros creemos que en este punto radica su actualidad. Se trata, en definitiva, de aceptar límites al conocimiento, pero sin renunciar a la indagación sistemática y la superación constantes, como si el investigador, que no ha perdido la fé en el progreso general del mundo y de la historia se dijera: "bueno, si no hemos llegado más lejos no es porque la realidad nos muestra al fin su muro impenetrable, sino porque nosotros no hemos podido aún ir más lejos». Se trata, pues, de un complejo sistemático de dedicación, tiempo y desarrollo del conocimiento.

En ese sentido, el buen método es el que mejor ayuda a una cabal descripción de la "realidad» concreta a la que se aplica, al mismo tiempo que puede usarse como un modelo instrumental, desde luego siempre revisable, para comparar estructuras semejantes. Desde esa postura, calificada de neo-kantiana, M. Weber rechaza el futurismo científico, aún cuando no sea posible evitar los juicios de valor. Pero estos deben ser tomados por el científico social como instrumentos, válidos para alcanzar ciertos fines y siempre teniendo en cuenta el coste social de tales medios: «No podemos... ir más allá. El uso de la ciencia empírica y del análisis lógico pueden mostrar a un individuo lo que le es posible lograr, cuáles serán las consecuencias de esta realización, y ayudarle a clasificar la naturaleza de sus ideales; pero la ciencia como tal no puede mostrarle qué decisión tomar» (14).

Aún más, el Weber que no puede separar tajantemente al científico del moralista, advierte, después de distinguir teóricamente la ética de la responsabilidad de la ética de la acción, que tiene que acabar subordinando ésta a aquella ya que, aplicando tal metodología a la lógica de la motivación política, se deducen dos consecuencias claves:

$1^{\text {a }}$. - «Ninguna ética en el mundo permite deducir cuándo y en qué medida el objetivo éticamente bueno justifica los medios y ramificaciones éticamente peligrosos» (15);

$2^{a}$. - «...hay un abismo lógico absoluto entre verdad fáctica y verdad

(14) ibid., p. 229.

(15) ibid., p. 229. 
ética, y (que) ninguna acumulación de conocimientos empíricos puede validar la prosecución de una ética más que otra» (16).

En resumidas cuentas, según Weber, pueden (y deben) hacerse descripciones científicas generales de la realidad sociohistórica, pero más que como leyes inmutables habría que tomarlas como medios de conocimiento en la necesaria elección de una realidad infinitamente divisible.. Esta forma de pensamiento, de alguna manera, creemos que propicia sustanciosamente los necesarios y siempre urgentes medios de conexión entre lo que se viene llamando "especialismo» y "enciclopedismo», intentos tan queridos como dificultosos en el amplio e intrincado campo de las ciencias sociales.

(16) ibid., p. 231. 